\title{
Peripheral CA 125 levels in patients with uterine fibroids
}

\section{P.Bischof ${ }^{1}$, M.A.Galfetti, J.Seydoux, J.U.von Hospenthal and A.Campana}

Department of Obstetrics and Gynaecology, University of Geneva, Geneva, Switzerland

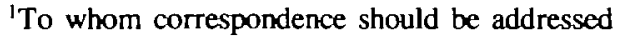

CA 125, a marker of ovarian cancer, is also increased in otherwise normal women suffering from, for example, pelvic inflammatory disease, endometriosis and adenomyosis. The tissues suspected of producing CA 125 in normal women include the endometrium, the ovary and the peritoneum. This study was based on the hypothesis that uterine myomata would distend the peritoneum covering the uterus and thereby increase the peripheral levels of CA 125 . To verify this hypothesis we measured CA 125 by an immunoradiometric assay in eight normal women every second day throughout the cycle and in 26 women with uterine fibroids before and after hysterectomy and at 8 and 12 weeks during gonadotrophin releasing hormone (GnRH) analogue therapy. In normal women no difference was observed between CA 125 levels in the follicular phase or in the huteal phase of the cycle. Over one-third $(10 / 26)$ of the patients with uterine fibroids had increased (> 90th centile of the controls) levels of CA 125 before GnRH therapy or hysterectomy. Removal of the uterus or administration of GnRH significantly decreased peripheral concentrations of CA 125 to levels below those observed in normal women. Furthermore, a significant positive correlation was observed between the levels of $C A 125$ and the volume of myomata as assessed by ultrasound. We conclude that in those cases of uterine fibroids where CA 125 is increased, monitoring this parameter during GnRH therapy is a good indirect measurement of regression of myomata. Key words: CA 125/uterine fibroids/GnRH therapy versus hysterectomy

\section{Introduction}

OC 125 is a murine monoclonal antibody recognizing a determinant on an antigen called CA 125 . The elevated serum concentrations of CA 125 are a well documented marker of epithelial ovarian tumours (Bast et al., 1981; Brioschi et al., 1987; Jacobs and Bast, 1989). Elevated serum CA 125 levels have, however, also been observed in women with no ovarian cancers but with advanced endometriosis (Patton et al., 1986), pelvic inflammatory disease (Takahashi et al., 1990), adenomyosis (Kijima et al., 1987), during menses (Takahashi et al., 1986) and during early pregnancy (Kobayashi $e t$ al., 1989; Bischof et al., 1989).

By immunohistochemistry, CA 125 has been localized in the epithelium of Fallopian tubes, endometrium and cervix but also in mesothelial cells of pleura, pericardium and peritoneum, whereas the ovary and its surface epithelium were negative for CA 125 (Kabawat et al., 1983; de Bruijin et al., 1986; Weintraub et al., 1990). The tissue(s) responsible for the production of CA 125 in normal women has not been identified with certainty. The endometrium is believed to be a potential source of CA 125 since endometrial cells (Bischof et al., 1986; Weintraub et al., 1990) or explants (Brumstead et al., 1990) release CA 125 in vitro and since CA 125 concentrations are particularly high in endometrial extracts (Jacobs et al., 1988). Despite the fact that CA 125 cannot be localized immunochemically in the ovary, this organ cannot be eliminated as a potential source of the antigen. Indeed, CA 125 levels were high in the luteal phase of women stimulated for in-vitro fertilization (IVF) or intra-uterine insemination but not in unstimulated cycles (Zweers et al., 1990). As suggested previously (Bischof $e t$ al., 1989), the peritoneum is probably a major source of circulating CA 125 at times other than pregnancy and menstruation, since CA 125 is immunolocalized in the mesothelial cells of the peritoneum and since pelvic inflammatory disease (Halila et al., 1987 ) or ruptured ectopic pregnancy (Bischof et al., 1989) greatly increase the serum levels of this antigen.

The purpose of the present study was to investigate the possible use of serum CA 125 to monitor the regression of uterine fibroids under gonadotrophin releasing hormone $(\mathrm{GnRH})$ therapy. This was based on the assumption that the presence of fibroids would distend the peritoneum covering the uterus and thereby increase CA 125 levels.

\section{Materials and methods}

The control group consisted of eight normal women (aged 28 to 35 years) with proven fertility in whom peripheral blood was obtained on ethylenediaminotetraacetate (EDTA, $2 \mathrm{mg} / \mathrm{ml}$ ) every 2 days starting immediately after the end of menstruation. Plasma was stored at $-20^{\circ} \mathrm{C}$ until assayed. Women with clinically diagnosed uterine fibroids $(n=26$, aged $22-55$ years) were divided into two groups: in group A $(n=16)$ the patients underwent a hysterectomy by the vaginal or the abdominal route. EDTA plasma was obtained prior to surgery and at 8 and 12 weeks thereafter and stored at $-20^{\circ} \mathrm{C}$. Uterine weight and dimensions were recorded on the surgical specimen and the uterine volume was approximated by multiplying the three dimen- 
sions. In group B $(n=10)$ the patients were treated by three to four injections of a GnRH-agonist (GnRHa; Decapeptyl Retard, $3.7 \mathrm{mg} /$ injection, Ferring, Switzerland) at 4-week intervals starting between days 20 and 25 of the cycle. The size of myomata was expressed as the product of three perpendicular diameters measured at ultrasound; this was assessed before and every 4 weeks during GnRHa treatment. EDTA plasma was obtained prior to and at 8 and 12 weeks during GnRHa treatment and stored at $-20^{\circ} \mathrm{C}$ until assayed. Cases with adenomyosis were excluded from group A based on analysis of the surgical specimen by the pathologist.

CA 125 was measured in all women using an immunoradiometric assay (Centocor, Medipro AG, Teufen, Switzerland). Luteinizing hormone $(\mathrm{LH})$ was measured in the control group by a commercially available radioimmunoassay (Biomérieux, Geneva, Switzerland).

Statistical evaluation was performed on a Macintosh computer by the Fastat program using Chi square, paired or unpaired $t$-test whenever appropriate.

\section{Results}

\section{CA 125 levels during the cycle, control group}

As shown in Figure 1, the levels of CA 125 plotted according to the $\mathrm{LH}$ peak, did not change between the follicle and the luteal phase of the cycle. For each patient, the mean CA 125 level during each phase was calculated by averaging the individual values. A paired $t$-test was used to evaluate the difference between phases. No difference was observed between phases (mean $\pm \mathrm{SEM}, 15.0 \pm 0.8$ versus $16.8 \pm 1.1$ for proliferative versus secretory; $P=0.08$; Table $I$ ), so that the normal value of CA 125 was calculated by averaging all values from all women.

The normal value of CA 125 during the cycle was $15.9 \pm 0.7 \mathrm{IU} / \mathrm{ml}$ (mean $\pm \mathrm{SEM}$ ) with 90th centile at $26.2 \mathrm{IU} / \mathrm{ml}$.

\section{CA 125 levels in women with uterine fibroids}

Before surgery or treatment, 10 out of 26 women with uterine fibroids has increased CA 125 levels (higher than the 90th centile of the normal population). This proportion was significantly higher than in normal women $\left(\chi^{2}=13.101, P<0.001\right)$. The mean concentration of CA 125 was also significantly higher in women with uterine fibroids as compared with normal women $(P<0.0001$, Table $)$. There was, however, no difference in these parameters between those women who underwent hysterectomy and those who received GnRHa (Table I). After hysterectomy or during GnRHa therapy, the levels of CA 125 progressively and significantly decreased (paired $t$-test, $P=0.004$ and 0.009 for hysterectomy and GnRHa treatment respectively) to levels observed during the cycle (Figure 2, Table I) with no difference between patients subjected to hysterectomy or GnRHa therapy. By 12 weeks of GnRHa treatment or 12 weeks after hysterectomy, the levels of CA 125 were significantly $(P<0.05)$ lower than those in the control group (Table I). In terms of lowering the peripheral CA 125 concentrations, both treatments were equally efficient.

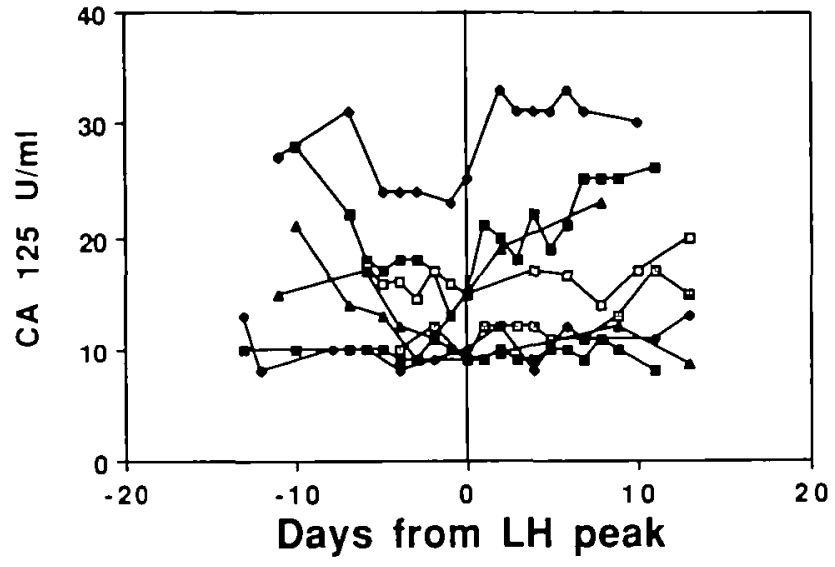

Fig. 1. Concentration of CA 125 throughout the cycle in eight normal women. Blood was not sampled during menses. $\mathrm{LH}=$ luteinizing hormone.

Table I. Peripheral concentrations of CA 125

\begin{tabular}{lrlrll}
\hline Type & $n$ & CA $125 \mathrm{IU} / \mathrm{ml}$ & SEM & Median & $n$ above*** \\
\hline Cycle control: Luteal* & 52 & $16.8^{\mathrm{a}}$ & 1.1 & 13.5 & $7 / 52$ \\
Follicular $^{*}$ & 52 & $15.0^{\mathrm{b}}$ & 0.8 & 14.2 & $3 / 52$ \\
Both* $^{*}$ & 103 & $15.9^{\mathrm{c}}$ & 0.7 & 14.0 & $10 / 103^{*}$ \\
\hline
\end{tabular}

Uterine fibroids before treatment:

\begin{tabular}{lllrll} 
for Hysterectomy & 16 & $45.2^{\mathrm{d}}$ & 13.1 & 18.0 & $7 / 16$ \\
for GnRHa $^{+}$ & 10 & $26.5^{\mathrm{c}}$ & 6.3 & 21.5 & $3 / 10$ \\
Both & 26 & $38.0^{\mathrm{f}}$ & 8.5 & 21.5 & $10 / 26^{\prime}$ \\
\hline
\end{tabular}

Uterine fibroids during or after treatment:

$\begin{array}{llllll}8 \text { weeks post-hysterectomy } & 16 & 19.0^{8} & 3.5 & 11.0 & 4 / 16\end{array}$

$\begin{array}{llllll}8 \text { weeks of GnRHa } & 10 & 12.5^{\mathrm{h}} & 2.2 & 10.5 & 1 / 10\end{array}$

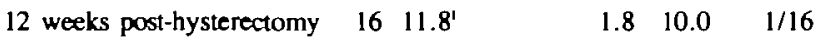

$\begin{array}{llllll}12 \text { weeks of } \mathrm{GnRHa} & 10 & 11.7 \mathrm{j} & 2.8 & 8.0 & 1 / 10\end{array}$

Paired $t$-test: $\mathrm{d}$ versus $\mathrm{g}, P<0.02$; $\mathrm{d}$ versus $\mathrm{i}, P<0.004$; $\mathrm{e}$ versus $\mathrm{h}$, $P<0.02$; e versus j, $P<0.001$.

Unpaired $t$-test: $\mathrm{c}$ versus $\mathrm{f}, \quad<0.0001 ; \mathrm{c}$ versus $\mathrm{i}, P<0.05$; $\mathrm{c}$ versus $\mathrm{j}$, $P<0.05$.

Chi square: $\mathrm{k}$ versus $1, P<0.0001$

* Mean from the 8 normal women (see Figure 1).

**n above: numbers of values above the 90th centile of the control group (cycle control).

${ }^{+} \mathrm{GnRHa}=$ gonadotrophin releasing hormone agonıst

\section{CA 125 levels and uterine size}

Among the patients who underwent a hysterectomy, there was no correlation between the preoperative levels of CA 125 and either the weight or the volume of the uterus as measured on the surgical specimen. In contrast, in women who were treated with GnRHa and on whom monthly ultrasound scans allowed determination of the size of the myomata, the volume of these was significantly correlated with the levels of CA 125 before and during treatment $(r=0.442, P<0.001)$. As shown in Figure 3, in women myomata of $<100 \mathrm{ml}$ the levels of CA 125 (mean $\pm \mathrm{SEM}, 14.3 \pm 1.9 \mathrm{IU} / \mathrm{ml}$ ) were significantly lower $(P<0.01)$ than in those with myomata volumes of $>500 \mathrm{ml}$ (mean $\pm \mathrm{SEM}, 33.0 \pm 15.9 \mathrm{IU} / \mathrm{ml}$ ). 


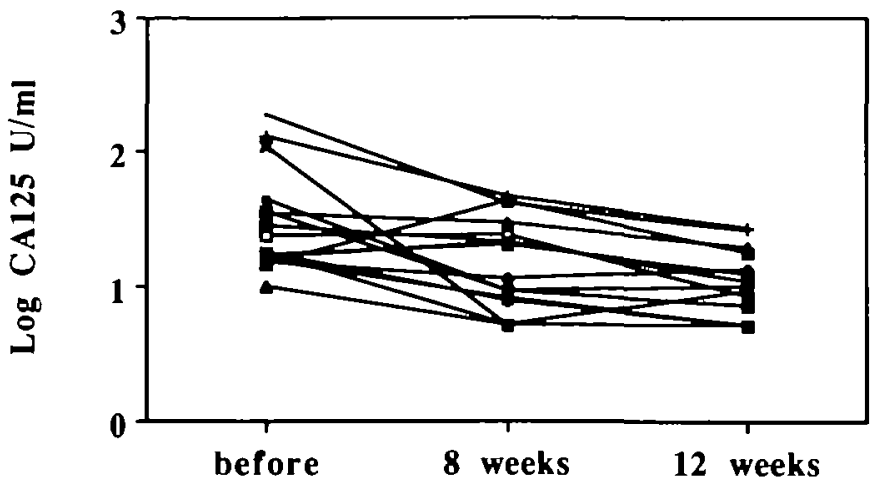

Time from Hysterectomy

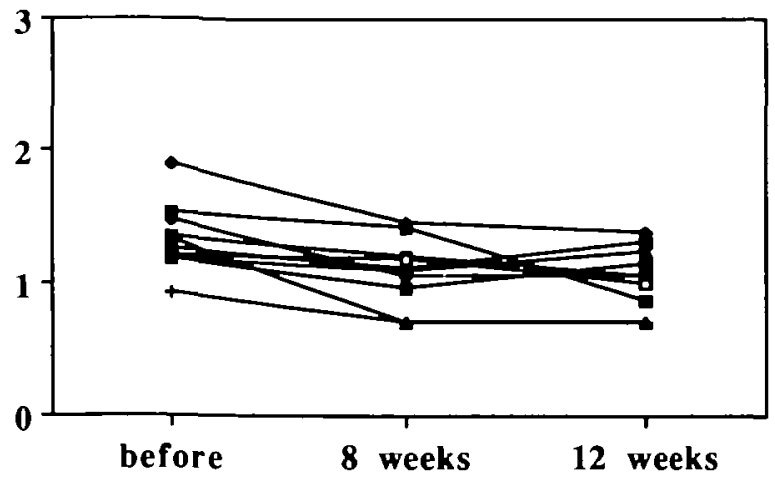

Time during GnRH treatment

Fig. 2. Concentration of CA 125 in women with uterine fibroids, before and after hysterectomy (left panel) and before and during gonadotrophin releasing hormone agonist ( $\mathrm{GnRHa}$ ) therapy.

\section{Discussion}

The CA 125 levels in normal women observed here correspond to those described by others (Jacobs $e t$ al., 1988; Lanzone et al., 1990), with no difference between the follicular and the luteal phases of the cycle. The levels are, however, in contrast to those observed by Jäger $e t$ al. (1988) who reported an increase of CA 125 which paralleled the growth of the dominant follicle. Their observation is difficult to reconcile with the unchanging levels of CA 125 during the first half of the cycle in women stimulated for in-vitro fertilization (Lanzone et al., 1990; Zweers et al., 1990) or with the absence of a difference between ovulatory and anovulatory cycles (Lehtovirta et al., 1990).

In this study, more than one-third of the women with uterine fibroids had increased CA 125 levels before surgery or treatment. This observation is at variance with a study by Halila et al. (1987) in which only two out of 11 women with uterine fibroids had increased ( $>35 \mathrm{IU} / \mathrm{ml}$ ) CA 125 levels before treatment. In the present study, 10 out of 26 such women had levels of CA 125 above the 90th centile of the control group $(26.2 \mathrm{IU} / \mathrm{ml})$ and among those, seven had values $>35 \mathrm{IU} / \mathrm{ml}$, reaching as high as $191 \mathrm{IU} / \mathrm{ml}$. The discrepancy between these studies remains unexplained. Since peripheral levels of CA 125 are correlated with the volume of the myomata, and since increased $(>26.2 \mathrm{IU} / \mathrm{ml}$ ) CA 125 levels are mostly seen in women with large (>300 ml) myomata, it is possible that in the study of Halila et al. (1987), the majority of women had smaller uterine fibroids. Here we observed that in women with fibroids, hysterectomy or GnRHa therapy decreased the CA 125 concentrations to values significantly below those of the control group. Thus in cases where CA 125 is increased before treatment, this parameter could serve to monitor GnRHa-induced myomata regression.

The origin of this increased CA 125 in women with uterine fibroids is a matter of speculation. The uterus probably only partially contributes to circulating CA 125 , since after hysterectomy or GnRHa therapy the peripheral levels of CA 125 are only slightly lower than during the normal cycle. However, since the levels are still measurable after hysterectomy, a contribution from another source has to be considered. The ovary could potentially be a source of CA 125 but since in normal women levels of CA 125 are identical in the ovarian vein and

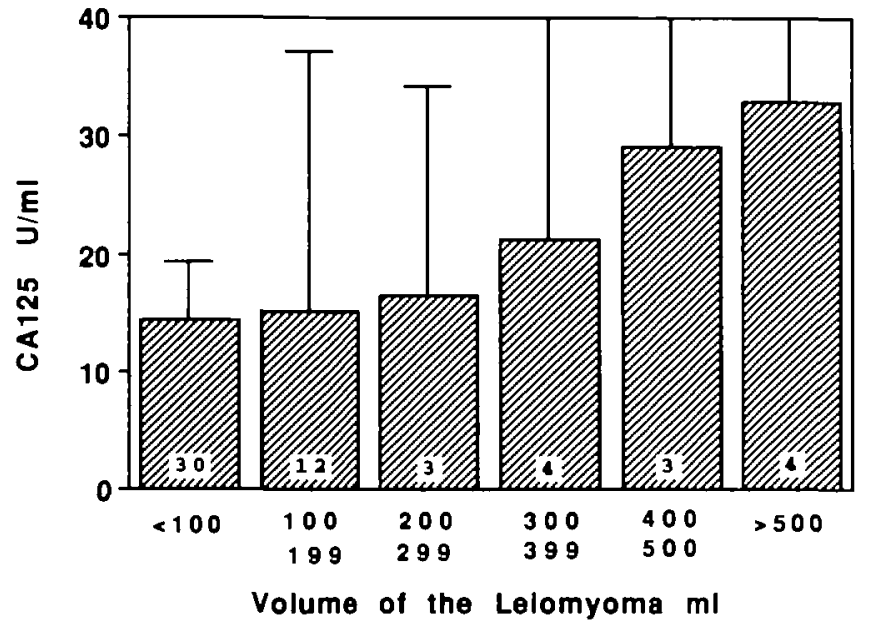

Fig. 3. Relationship between peripheral CA 125 concentration and the volume of leiomyomas as measured by ultrasound $(n=56$ pairs of observations including values before and during therapy).

peripherally, (Bischof et al., unpublished), we considered it unlikely that the ovary contributes significantly to the circulating CA 125 in non-stimulated women. It is tempting to speculate that the source of CA 125 is the peritoneum, since CA 125 was localized immunohistochemically in this tissue (Kabawat $e t$ al., 1983) and since serum CA 125 is increased in pelvic inflammatory disease (Takahashi et al., 1990), in ruptured ectopic pregnancies (Bischof et al., 1989) or after laparoscopy for oocyte retrieval (Zweers $e t$ al., 1990). If the peritoneum is a source of CA 125 in vivo, then the increased levels of CA 125 in women with uterine fibroids could be explained by peritoneal distension due to the myomata. It must be added that the stratification of the CA 125 values according to the location of the fibroids did not show any significant difference between intramural, submucosal or subserosal fibroids.

\section{Acknowledgements}

The authors wish to thank Mrs C.Gruffat for her skilful technical help and Miss M.Gharbi for typing the manuscript. 


\section{References}

Bast,R.C., Freeney,M., Lazarus,H., Nadler,L.M., Colvin,R.B. and Knapp,R.C. (1981) Reactivity of a monoclonal antibody with human ovarian carcinoma. J. Clin. Invest., 68, 1331-1337.

Bischof,P., Tseng,L., Brioschi,P.A. and Hermann,W.L. (1986) Cancer antigen 125 is produced by human endometrial stromal cells. Hum. Reprod., 1, 423-426.

Bischof,P., Mignot,T.M. and Cédard,L. (1989) Are pregnancyassociated plasma protein-A (PAPP-A) and CA 125 measurements after IVF-ET possible predictors of early pregnancy wastage? Hum. Reprod., 4, 843-847.

Brioschi,P.A., Irion,O., Bischof,P., Bader,M., Forni,M. and Krauer,F. (1987) Serum CA 125 in epithelial ovarian cancer. A longitudinal study. Br. J. Obstet. Gynaecol., 94, 196-201.

Brumstead,J.R., McBean,J.H., Deaton,J.L. and Gibson,M. (1990) CA 125 secretion by luteal phase endometrium in vitro. Hum. Reprod., $5,682-684$.

de Bruijin,H.W.A., van Beeck Calkoen-Carpay,T., Duk,J.M., Aalders,J.G. and Fleuren,G.J. (1986) The tumor marker CA 125 is a common constituent of normal cervical mucus. Am. J. Obstet. Gynecol., 154, 1088-1091.

Halila,H., Suikkari,A.M. and Seppälä,M. (1987) The effect of hysterectomy on serum CA 125 levels in patients with adenomyosis and uterine fibroids. Hum. Reprod., 2, 265-266.

Jacobs,I. and Bast,R.C. (1989) The CA 125 numour associated antigen: a review of the literature. Hum. Reprod., 4, 1-12.

Jacobs,I.J., Fay,T.N., Stabile,I., Bridges,J.E., Oram,D.H. and Grudzinskas,J.G. (1988) The distribution of CA 125 in the reproductive tract of pregnant and non pregnant women. Br. J. Obstet. Gynaecol., 95, 1190-1194.

Jäger,W., Meier,C., Wildt,L., Sauerbrei,W. and Lang,N. (1988) CA 125 senum concentration during the menstrual cycle. Fertil. Steril., 50, 223-227.

Kabawat,S.E., Bast,R.C., Bhan,A.K., Welch,W.R., Knapp,R.C. and Colvin,R.B. (1983) Tissue distribution of a coelomic epithelium related antigen recognized by the monoclonal antibody OC 125 . Int. J. Gynecol. Pathol., 2, 275-285.

Kijima,S., Takahashi,K. and Kitao,M. (1987) Expression of CA 125 in adenomyosis. Gynecol. Obstet. Invest., 23, 122-125.

Kobayashi,F., Sagawa,N., Nakamura,K., Nonogaki,M., Ban,C., Fujii,S. and Mori,T. (1989) Mechanism and clinical significance of elevated CA 125 levels in the sera of pregnant women. Am. J. Obstet. Gynecol., 160, 563-566.

Lanzone,A., Fulghesu,A.M., Guida,C., Muscatello,R., Caruso,A. and Mancuso,S. (1990) Serum CA 125 levels do not depend on ovarian steroidogenesis. Fertil. Steril., 54, 415-418.

Lehtovirta,P., Apter,D. and Stenman,U.H. (1990) Serum CA 125 levels during the menstrual cycle. Br. J. Obstet. Gynaecol., 97, 930-933.

Patton,P.E., Field,C.S., Harms,R.W. and Coulam,C. (1986) CA 125 levels in endometriosis. Fertil. Steril., 45, 770-773.

Takahashi,K., Yoshino,K., Araki,Y., Nishigaki,A., Shirai,T., Shibukawa,T. and Kitao,M. (1986) Alteration in levels of CA 125 during the menstrual cycle. Jap. J. Fertil. Steril., 31, 392-396.

Takahashi,K., Nagata,H., AbuMusa,A., Shibukawa,T.,Yamasaki,H. and Kitao,M. (1990) Clinical usefulness of CA 125 levels in the menstrual discharge in patients with endometriosis. Fertil. Steril., 54, $360-362$.

Weintraub,J., Bischof,P., Tseng,L., Redard,M. and Vassilakos,P. (1990) CA 125 is an excretory product of human endometrial glands. Biol. Reprod., 42, 721-726.

Zweers,A., De Boever,J., Serreyn,R. and Vandekerckhove,D. (1990) Correlation between peripheral CA 125 levels and ovarian activity. Fertil. Steril., 54, 409-414.

Received on June 11, 1991; accepted on August 15, 1991 